\title{
DASAR ALKITABIAH DALAM MENGAJAR ANAK
}

\section{APA ITU MENGAJAR}

\section{Mengajar dalam pandangan Kristen}

- Mengajar berarti memberi pengajaran yang benar sampai menghasilkan perubahan. Untuk menentukan perubahan yang alami kita harus melihat kepada firman Tuhan (standar kita yang tidak pernah salah untuk mempertimbangkan seluruh tujuan dari pengajaran Kristen)

- "Yesus Kristus, sang guru Agung adalah standar dan teladan bagi guru dan pengajaran Kristen."

- Mengajar adalah dari hati bukan dari kepala.

Mengajar adalah melihat,

... mendengar

... belajar,

... mengasihi,

Mengajar adalah melihat dan memperhatikan,

... memperdulikan dan mendengar,

... belajar dan menanggapi,

... mengasihi dan menjangkau.

Mengajar anak, khususnya mengajarkan firman Tuhan kepada anak adalah tanggung jawab yang besar, karena disitulah dasar iman diletakan.

\section{MENGAPA KITA HARUS MENGAJAR ANAK}

- Mengajar anak adalah kehendak Allah.

1. Ulangan $6: 4-7 \mathrm{a} \quad$;

2. Amsal 22:6

3. Ulangan 11:18-19 ;

4. Mazmur 78:2-8

5. Matius 28: 19-20 ;

6. Markus 10:4 


\section{- Anak membutuhkan Juruselamat}

\section{Anak adalah orang berdosa}

- Mazmur 51:7 ;

- Roma 3:23 ;

- Kejadian 8:21 ;

- Matius 18:14 ;

\section{Anak dapat percaya}

- Markus 10:15 ;

- II Timotius 3:5 ;

- Mengajar anak berakibat besar

1. Amsal 22: 6

2. Maz 8:2 \& Mat 21:15-16;

3. Amsal 29:15,17 \& 28:7 ;

4. Ester, Daniel, Yusuf, Timotius

Salah satu contoh dalam Perjanjian Lama adalah Musa. Walaupun terdidik selama 40 tahun di Mesir dengan kebudayaan dan kepercayaan Mesir, imannya tak tergoyahkan bahkan menjadi pemimpin besar sepanjang sejarah. Ini disebabkan karena orang tuanya tahu memanfaatkan masa kecil Musa dengan ajaran-ajaran Firman Allah.

Dalam Perjanjian Baru kita bisa belajar dari Iman Timotius yang bertumbuh sedari kecil karena pengaruh iman nenek dan ibunya, sebagaimana yang dikatakan dalam 2 Timotius 1:5, "Sebab aku teringat akan imanmu yang tulus ikhlas, yaitu iman yang pertamatama hidup di dalam nenekmu Lois dan di dalam ibumu Eunike dan yang aku yakin hidup juga di dalam dirimu".

Abraham Lincoln mantan presiden Amerika Serikat yang termasyur dan bermoral tinggi mengatakan, "Ajar seorang anak untuk mengenal Kristus. Ajarlah mereka ketika masih berusia 6 tahun, dan mereka akan tahu bagaimana bertobat dan beriman kepada Kristus seperti seorang dewasa".

Paul D. Meier seorang ahli pendidikan juga mengatakan; "Pribadi atau watak seorang anak terbentuk pada usia 0-7 tahun yang menentukan 'siapa dia' pada masa dewasa kelak". 


\section{INTI PENGAJARAN}

“Membawa Anak Mengenal Yesus dan Menjadikannya Saksi”

\section{Injil untuk Setiap Orang}

Allah murid-murid untuk memberitakan Injil kepada segala makhluk (Markus

16:15). Kasih Allah disediakan untuk orang didunia ini (Yohanes 3:16).

Janji keselamatan tidak diberikan dengan batasan usia.

Yohanes 3:16 “......setiap orang yang percaya......”.

Yohanes $1: 12$ “.......semua orang yang menerimanya......”.

Roma 10:13 “.......barangsiapa yang berseru......"

\section{Anak-anak Terhilang}

Anak-anak mempunyai dosa

Roma 3:23, "Karena semua orang telah berbuat dosa dan telah kehilangan kemuliaan Allah."

Roma 5:12, "Sebab itu, sama seperti dosa telah masuk ke dalam dunia oleh satu orang, dan oleh dosa itu juga maut, demikianlah maut itu telah menjalar kepada semua orang, karena semua orang telah berbuat dosa"

- Anak-anak perlu menyadari akan keadannya dihadapan Allah. Bahwa dirinya (anakanak) juga termasuk orang BERDOSA dan harus mengalami KELAHIRAN BARU

David Livingstone seorang misionari dan penjelajah asal Skotlandia berkata : "Urusan kita adalah mengajar anak-anak tentang dosa dan juruselamat, bahkan tanpa gambaran tentang usia tertentu untuk menerima Kristus. Roh Kudus pada waktunya akan menyadarka mereka akan dosanya. Apabila Roh Kudus menyadarkannya akan dosanya, usia berapa saja, siapakah kita yang berani mencampuri pekerjaanNya? Disetiap waktu, seperti ini, kita tunjkkan persaan simpati kita. Setiap anak sudah cukup usia untuk menerima Kristus ketika 
dia menyadari bahwa dosanya melawan Allah dan oleh karena dosa itu, dia akan terhilang tanpa Kristus.

\section{Pengajaran Kristus tentang Anak-Anak}

\section{Tuhan Yesus menempatkan nilai yang besar akan seorang anak kecil}

"Maka Yesus mengambil seorang anak kecil dan menempatkannya di tengah-tengah mereka, kemudian ia memeluk anak itu dan berkata kepada mereka, Barangsiapa menyambut seorang anak seperti ini dalam namaKu, ia menyambut Aku. Dan barangsiapa menyembut Aku, bukan akau yang disambutnya, teteapi yang mengutus aku." (Markus 9:36-37)

- Usia anak-anak yang akan diinjili sering diperdebatkan. Kristus melalui hal ini dengan tegas berbicara tentang seorang anak kecil --- Anak Kecil = Paidion. Markus 9:36 Menunjukkan bahwa anak itu masih kecil - "Dia memeluk anak itu."

- Syarat orang dewasa masuk kedalam kerajaan Allah harus seperti anak kecil, bergantung dengan rendah hati kepada Tuhan.

- Orang dewasa harus kembali pada hati seperti anak kecil, bukan tingkah laku. Anak-anak hidup dalam suasana ketergantungan yang wajar.

\section{Anak-anak lebih siap untuk menerima Juruselamat}

- "Dan barangsiapa menyambut seorang anak seperti ini dalam namaKu, ia menyambut Aku. Tetapi barangsiapa menyesatkan salah satu dari anak-anak kecil ini yang percaya kepadaKu....."(Matius 8: 5-6)

- Kristus menegaskan ini adalah iman yang menyelamatkan; "percaya kepadaKu” adalah kata-kata yang sama dipakai dalam Yohanes 3:6, Kisah 16:31. Kita diingatkan untuk tidak melukai hati anak-anak yang percaya.

- Kristus memeberikan peringatan kedua tentang menganggap remeh anak-anak (ayat 10). Anak Kecil $=$ mikros .

"Demikian juag Bapamu yang di sorga tidak menghendaki supaya seorangpun dari anak-anak ini hilang." (Matius 18:14) 
- Kristus mengajarkan betapa pentingnya seorang anak (ayat12). Bersukacita atas setiap anak yang diselamatkan (ayat13). Dia tidak akan menghendaki satupun binasa (ayat 14).....Anak Kecil = mikros .

\section{Anak-anak Dapat Bertobat}

Beberapa orang ragu dan sulit percaya pada kenyataan bahwa anak bisa bertobat. Bagaimanapun juga, tidak ada ayat dalam Alkitab yang berkata bahwa anak tidak dapat datang dalam hubungan secara pribadi dengan Allah melalui iaman dalam Yesus Kristus.

$\checkmark$ Anak-anak memiliki hati yang terbuka, dan siap

$\checkmark$ Anak-anak secara alami rendah hati, mudah diajar,dan percaya

$\checkmark$ Besok, hati anak yang mudah dipengaruhi dakan menjadi keras terhadap Tuhan dan Firmannya

\section{Tahapan-Tahapan Kelahiran Baru:}
a. Roma 3:23, 6:23
b. Yohanes 3:16
c. 1 yohanes 1:7-9
d. Yohanes 3:18,36,6,47
e. Efesus 2:10, I Korintus 6: 20 ;
f. I Yohanes I:7,9 Filipi 4:8-9 ;

Dalam sebuah khotbah Charles Spurgeon, menyatakan : "Seorang anak usia 5 tahun, jika diajar dengan benar, dapat sungguh-sungguh percaya dan mengalami kelahiran baru sama seperti seorang dewasa. Saya yakin petobat baru dari anatara anak-anak adalah yang terbaik yang kami miliki. Saya menilai mereka itu lebih sungguh-sungguh dari kelompok yang lain, lebih stabil dan dalam jangka panjang, lebih kokoh.

\section{Anak-anak lebih lama waktunya untuk melayani Tuhan}

$\checkmark$ Banyak Pengkotbah dan para penginjil yang diselamatkan pada saat usia anak-anak

$\checkmark$ Banyak tokoh-tokoh Kristen yang juga bertobat pada usia anak-anak. 
Tokoh gereja yang bernama Polykarpus murid dari Irenius dan Irenius adalah murid rasul Yohanes telah membuktikan imannya yang murni yang telah dia terima sejak kecil. Sebelum ia dibakar hidup-hidup oleh orang-orang Romawi karena tidak mau menyangkal Tuhan Yesus, ia berkata demikian, "Selama 84 tahun Tuhan Yesus tidak pernah bersalah satu kalipun kepadaku, dan Ia begitu mengasihiku, bagaimana mungkin saya melarikan diri dari bahaya, demi keselamtan diriku sendiri, menghujat nama-Nya. Silahkan jika anda mau membakar saya sampai mati, saya tidak tega melawan Tuhan. Dia sudah menunggu saya”. Iman yang tak tergoyahkan ini terbentuk, karena Polykarpus tahu jelas apa artinya menerima Kristus dan bertobat pada waktu ia berusia 9 tahun. Jadi saat seusia 9 tahun, ia sudah mempunyai pengalaman mencintai Tuhan, lalu kesadaran itu terus ada selama 84 tahun dengan baik, dan ia menjadi sedemikian kuat iman dan tidak menyangkal Tuhan.

Stephen Olford "Saya percaya tentang penginjilan anak karena ada tiga alasan, Pertama sebab saya lahir baru pada usia 7 tahun; kedua, sebab sejarah secara umum menunjukkan bahwa jumlah terbesar orang-orang bertobat adalah sebelum berusia 20 tahun; ketiga, karena Alkitab menjelaskan bahwa masa muda adalah waktu untuk kembali pada Allah”.

\section{Anak-anak Adalah Masa Depan Bangsa Kita}

- Allah memperingatkan bahwa jika anak-anak tidak diajar, maka generasi yang akan datang berhenti melakukan dan menaati Firman-Nya

- Lihat contoh dalam Hakim-hakim 2:10-11\& Mazmur 78:1-8

Nilai-nilai pendidikan Kristen yang ditanamkan sejak dini kepada anak-anak melalui Sekolah Minggu sangat bermanfaat bagi pertumbuhan rohani anak sebagai generasi penerus. Hal ini disebabkan pertama, hati seorang anak dihadapan Tuhan adalah murni dan terbuka, sehingga merupakan hal yang sangat mendasar, yang membuat anak-anak tersebut menjadi percaya. Pemikiran apapun yang disalurkan oleh orang dewasa semuanya dapat mempengaruhi mereka. Kedua, menerima Tuhan pada masa anak-anak, berarti sepanjang hidupnya dapat dipakai oleh Tuhan dibandingkan dengan mereka setelah dewasa baru percaya. Ketiga, daya ingat anak-anak yang sangat kuat, merupakan masa yang terbaik untuk menghafal ayat Alkitab. Ayat-ayat yang dihafal pada masa anak-anak dapat dingat pada jangka waktu yang lama bahkan lebih efesien sehingga ayat-ayat tersebut dapat berfungsi 
pada saat-saat penting dalam hidup mereka. Keempat, pembinaan karakter orang kristen dapat berakar semakin mendalam pada usia yang dini dan tidak muda berubah.

Mary Go berpendapat bahwa membina generasi penerus, berarti juga membina pemimpin-pemimpin gereja dimasa yang akan datang, jikalau Sekolah Minggu berhasil membina kerohanian generasi penerus, itu berarti telah melatih dan mempersiapkan para pemimpin gereja untuk masa yang akan datang. Mereka tidak mudah terbawa arus karena telah memiliki dasar iman yang diletakkan pada masa anak-anak.

- Jika Anda memenangkan seseorang anak bagi Kristus, anda menyelamatkan seluruh kehidupannya

Jika anda memenangkan seseorang dewasa, anda hanya menyelamatkan satu jiwa saja.

- Sekaranglah ada waktunya untuk menjangkau anak-anak (2 Korintus 6:2)

Billy Sunday, seorang penginjil terkenal berkata "satu-satu cara di bumi yang diciptakan Allah di mana anda dapat menyelesaikan masalah menjangkau massa adalah mendapatkan anak-anak."

Ingat, Roh Kuduslah yang menyadarkan hati anak-anak akan dosa-dosanya dan menyebabkan dia siap untuk menerima Kristus sebagai Juruselamat (Yoh 16:8)

Ingatlah juga, bahwa anak-anak tergantung kepada kita (GURU) untuk menunjukkan jalan Keselamatan itu kepada mereka. 


\section{GURU DALAM PANDANGAN ALLAH}

Air yang jernih membutuhkan saluran yang bersih!

Seorang guru yang mengajar Alkitab merupakan saluran Air Hidup bagi anak.

Dapatkah ia mengalirkan air yang datang dari Tuhan, tanpa disucikan sebelumnya?

Dapatkah ia membawa anak samapai mengenal Tuhan Yesus secara pribadi, tanpa mengenal Dia secara pribadi?

\section{PENTINGNYA SEORANG GURU}

Anda mungkin menjadi salah satu dari banyak guru yang memberikan petunjuk dalam perjalanan hidup seorang anak.

1. Pertimbangkan ini: karena anak bisa tidak memiliki orang lain yang mengajarkannya Firman Tuhan, sering guru berdiri dantara anak dan suara Allah.

2. Kehidupan dan pribadi guru adalah kunci dalam pengajaran Kristen.

- 'Guru adalah seseorang dari siapa, melalui siapa atu dengan siapa murid belajar.'

- "Factor penting yang sangat mempengaruhi belajar adalah hidup dan pribadi guru."

- "Guru dapat mengajar sedikit dari apa yang dikatakannya; semakin banyak dari yang dilakukannya; tetapi paling banyak lagi dari pribadinya."

- "Kita sebagai guru Kristen harus kembali kepada guru Agung sebagai inspirasi kita, kepuasan kita, motivasi kita yang sah untuk bertindak sebagi orang Kristen dan sebagai prinsip yang benar serta metode yang tepat untuk mencapai tujuan.”

3. Mengajar adalah hak istimewa.

4. Mengajar adalah tanggung jawab, satu tanggung jawab yang besar!

...untuk belajar melihat kebutuhan

... untuk menghidupkan pelajaran 
... untuk menjadi pemimpin, pelajar, pendengar

... untuk bergantung sungguh-sungguh kepada Roh Kudus yang memampukan

... untuk menykan kebenaran Firman Tuhan

... untuk serius dengan posisinya sebagai guru (Yakobus 3:1)

\section{Sekilas Mengenai Guru}

1. Keyakinan guru harus kepada Tuhan saja

2. Komitmen guru kepada Tuhan harus terbukti.

Itu akan terlihat dalam penampilan pribadinya; rapi dan cara berakaian yang pantas dalam setiap situasi. Itu akan terlihat juga dalam cara dia berdiri menyampaikan firman Allah: sikap yang baik berarti menunjukkan penguasaan diri yang baik.

3. Seseorang yang mengajar firman Tuhan kepada anak-anak harus yakin akan Keselamatan.

4. Seorang guru perlu bersikap baik terhadap dirinya sendiri, anak-anak dan literatur/bahan ajar yang digunakan.

5. Akrostik singkat yang menyimpulkan beberapa kualitas dan cirri guru dapat dipergunakan.

$$
\begin{aligned}
& \text { T (Teachable)_-Mudah belajar } \\
& \text { E (Enthusiastic)—Bersemangat }
\end{aligned}
$$

A (Approachable) — mudah didekati

C (Consecrated) - berserah

H (Honest)_-Jujur

E (Enduring) - Tabah

$\mathbf{R}$ (Ready) - Siap

$$
\text { S ( Sensitive)—Peka }
$$

6. Tujuan utama guru Kristen adalah

- Untuk melihat Tuhan Yesus Kristus diagungkan, dimuliakan, dan ditinggikan melalui pengajaran Firman Tuhan.

- Untuk memenangkan setiap anak bagi Kristus sebagai Juruselamatnya.

- Untuk membimbing setiap anak yng sudah selamat dalam mempelajari Alkitab secara sistematis.

- Untuk melatih orang-orang Kristen yang terbeban untuk menjangkau dan memenangkan anak-anak bagi Kristus. 


\section{PERAN SEORANG GURU SEKOLAH MINGGU}

Seorang Guru Sekolah Minggu mempunyai peranan penting di gereja dalam proses pendidikan rohani anak. Guru Sekolah Minggu merupakan perpanjangan tangan Majelis Jemaat dalam pembinaan terhadap anak-anak. Adapun yang menjadi tugas dan panggilan seorang Guru Sekolah Minggu terhadap anak-anaknya ialah:

- Mengajar ( I Timotius 2: 7). Guru sekolah Minggu menyampaikan pokok-pokok iman yang menjadi dasar kehidupan kekristenan.

- Memberikan teladan ( I Kor.11:1; Filipi 3: 7; I Tim. 4: 11-13). Seorang Guru Sekolah Minggu akan mempunyai pengaruh yang luar biasa terhadap muridnya karena mereka mudah sekali meniru tutur kata dan tingkah laku gurunya. Oleh sebab itu, Guru Sekolah Minggu perlu selalu memperhatikan dirinya sendiri apakah ia telah menjadi teladan yang baik bagi muridnya; baik ketika berada di dalam kelas maupun ketika berada di luar ruangan Sekolah Minggu.

- Menginjili (I Timotius 2: 7). Dalam mengajar seorang Guru Sekolah Minggu tidak menyampaikan kebenaran iman kristen, tetapi juga memberitakan kabar baik bahwa Allah mengasihi manusia supaya jiwa anak-anak diselamatkan.

- Mendoakan (II Timotius 1: 11-12). Mendoakan anak-anak dan keluarganya merupakan bagian penting yang harus doilakukan oleh seorang Guru Sekolah Minggu untuk menjalin komunikasi dan keakraban dengan anak-anak dan orangtuanya.

- Menggembalakan (Yehezkiel 34:2-6; Yohanes 10:11-18). Seorang Guru Sekolah Minggu tidak hanya pengajar tetapi juga gembala bagi domba-dombanya. Seorang gembala yang baik mengenal dan mengasihi setiap dombanya; dan tidak akan membiarkan seekor domba pun berada dalam kesulitan. Itulah juga peran yang harus dilakukan oleh Guru Sekolah Minggu. Ia harus mengenal dan membimbing anak-anak yang berada di kelasnya dan menolong anak-anak yang sedang mengalami kesulitan sejauh yang dapat dilakukannya. Pelawatan anak (dan tentunya juga kepada 
orangtuanya) merupakan hal penting lainnya yang harus dan perlu dilakukan oleh Guru Sekolah Minggu.

\section{Doa seorang ANAK tentang gurunya TUHAN.....}

Sudah 120 kali aku meminta kepada-Mu Agar Tuhan mengganti guru Sekolah Mingguku.

Jangan kirim kepadaku guru yang malas dan tidak siap mengajar,

Jangan kirim kepadaku guru yang sering terlambat,

Jangan kirim kepadaku guru yang ketus lagi galak,

Jangan kirim kepadaku guru yang tidak sayang padaku

TETAPI .....

\section{TUHAN YESUS......}

Kirimkanlah kepadaku guru yang baik seperti YESUS

Tidak usah bagus suaranya, namun ramah senyumnya, Tidak usah cantik parasnya, namun menarik pribadinya,

Tidak usah tegap badannya, namun lembut hatinya,

Tidak usah bagus ceritanya, namun Kristus hidupnya,

$$
\text { AGAR.... }
$$

Ketika aku sedih aku dapat menangis bersamanya, Ketika aku gembira, aku dapat tertawa bersamanya. Ketika papa dan mama berselisih paham, aku dapat Berdoa bersamanya.

TUHAN .... .

Aku ingin guru yang baik seperti

Tuhan Yesus.

Amin 
